\title{
Singularidade e sonho de permanência da sociedade escravista brasileira (Século XIX)
}

Uniqueness and permanence dream of Brazilian slave society (XIX Century)

Ênio José da Costa Brito*

\begin{abstract}
Resumo
Dentro de uma onda de estudos sobre a escravidão no Brasil dos últimos 50 anos temos o estudo original sobre a dimensão política da mesma a partir de documentação original (Anais e Arquivos) levado adiante por Tamis Parron. No Século XIX ocorreu, segundo o autor, uma politização das questões escravistas e não tanto o desenvolvimento de uma política da escravidão. O contrabando de escravos e a defesa da escravidão são eventos significativos demais para serem deixados de lado pela historiografia. Para Parron aspectos externos como a mudança da política escravagista norte-americana e a posição da Inglaterra interferiram claramente na política interna do Brasil. Entretanto, para o autor, não só houve a defesa da escravidão com o envolvimento claro do Estado nisto mas também jogos de cena política da parte dos que fossem contra. Alguns eventos indiretos como a Lei da Terra e a tráfico interno de escravos faziam parte de uma politização da temática da escravidão e por decorrência a manutenção da sociedade escravocrata.
\end{abstract}

Palavras-chave: Brasil: escravidão; escravidão; escravidão: contrabando.

\begin{abstract}
Within a sequence of studies on slavery in Brazil in 50 years, we have the original study on the political dimension of this slavery from original documentation (Annals and Archives) carried forward by Tamis Parron. In the nineteenth century occurred, according to the author, a politicization of slaveholding issues rather than the development of a policy of slavery. The smuggling of slaves and the defense of slavery are too significant to be set aside by historiography events. To Parron, external aspects such as change in American policy slavery and the position of England clearly interfered in the internal politics of Brazil. However, to the author, what existed was not only the defense of slavery with the clear involvement of the state, but also political game scenes by those who had different opinions. Some indirect events such as the Land Law and the domestic slave trade were part of a politicization of the issue of slavery and consequently, the maintenance of the slave society.
\end{abstract}

Keywords: Brazil: slavery; slavery; slavery: smuggling.

\footnotetext{
Comunicação submetida em: 08 de julho de 2014 e aprovado em: 02 de Setembro de 2014.

* Doutor em Teologia. Professor Adjunto da Pontifícia Universidade Católica de São Paulo. País de origem: Brasil.

E-mail: brbrito@uol.com.br.
}

Horizonte, Belo Horizonte, v. 12, n. 35, p. 987-1001, jul./set. 2014 - ISSN 2175-5841 
Brasil, século XIX. Nunca a liberdade foi tão defendida nos espaços públicos: nunca foram comprados tantos escravos nos mercados. Nunca a população livre recebeu tantas garantias constitucionais e dependeu tanto dos cativos para exercê-las. Nunca o tráfico foi tão combatido, e seu incremento, tão desejado. Essas contradições são tão mencionadas como pouco estudadas.Por que?.

\section{Introdução}

Os estudos sobre a escravidão no país vêm se renovando desde a década de 1960, renovação que se intensificou a partir da década de 1980, contudo a dimensão política permaneceu na sombra, pouco explorada pela historiografia. Em A política da escravidão no Império do Brasil, 1826-1865 (PARRON, 2011, p.373), Tâmis Parron se propõe a examinar as relações entre a instituição da escravidão e a política imperial brasileira.

O autor pretende realizar "uma análise que unisse, diacronicamente, enunciação parlamentar, formação partidária, articulação social, dinâmica do tráfico negreiro, transformações institucionais do aparelho de Estado e ações de escravo" entre 1826-1865 (PARRON, 2011, p.14).

Desafio nada simples, seja pelo arco de tempo que deseja cobrir, seja pela documentação a ser pesquisada - Anais da Câmara dos Senhores Deputados e Anais do Senado, Arquivos Históricos entre outras - , seja pelo diálogo cerrado com a historiografia nacional e internacional.

Parron elege a política da escravidão como vetor analítico para desvelar o íntimo conluio entre política e escravidão no Império, união tecida cuidadosamente pela elite política conservadora e pelos grandes proprietários de escravos ao longo do século XIX. Gradualmente, ao longo dos quatro capítulos, intitulados, 
Soberania, ordem social e escravidão, 1826-1865; Regresso e a política do contrabando negreiro,1835-1841; Grã-Bretanha, hegemonia saquarema e: contrabando: um Brasil todo africano , 1841-1850; e Coroa e Parlamento: poder político e escravidão na era do pós-contrabando, 1850-1865, o leitor toma conhecimento das estratégias discursivas e práticas que deram vida longa ao Império escravista brasileiro.

\section{A gestação da política da escravidão}

O autor toma como ponto de partida para identificar a política da escravidão a presença de D. João VI (1808-1821), período no qual se negociou com a Inglaterra a permanência do tráfico negreiro para a América portuguesa negociação concluída com a assinatura da Convenção Adicional de 28 de julho de 1817 ao tratado de 22 de janeiro de 1815. No entanto, a defesa da escravidão e do comércio de almas no Brasil impôs altos sacrifícios a Portugal. A Revolução do Porto e a convocação das Cortes de Lisboa (1820-1823) o confirmam.

Em 1820, o quadro ideológico, dentro do qual se discutia a escravidão, começa a mudar. "A revolução do Porto, os debates da Independência e a Constituição do Brasil brindaram ao país a chance de criar um repertório ideológico próprio segundo os princípios da cultura política liberal" (PARRON, 2011, p. 58), dando fôlego à instituição escravista, ao compaginar escravidão e igualdade de raças.

Para o autor, os negociantes de grosso trato teriam influenciado a Constituinte para prorrogar ao máximo a legalidade do tráfico negro, o que atenderia, também, os interesses do Estado, dependente de longa data desse segmento. 'Talvez não seja incorreto dizer que foi o governo joanino, e não os fazendeiros, quem desempenhou o papel de principal parceiro dos traficantes entre 1808 e 1820" (PARRON, 2011, p. 61). 
Entre 1824 e 1826, lutava-se no Parlamento para repassar o controle do comércio transatlântico do Executivo para a Câmara. A tensão entre a Câmara e D. Pedro I aumentou depois que ele ratificou a Convenção de 1826, com a Inglaterra, que estabelecia o prazo de três anos para a abolição da escravidão no país.

As discussões sobre o mérito da Convenção foram acaloradas. Cunha Matos (por Goiás) e Luis Augusto May (deputado por Minas Gerais), membros da Comissão de Diplomacia e Estatística da Câmara, que acolheu o acordo, em 16 de junho de 1827, foram votos vencidos, pois rejeitaram a validade da Convenção. Para Cunha Matos, a abolição instauraria uma crise sistêmica que contaminaria das atividades navais à agricultura.

A estratégia dos deputados era bem clara:

propagando que o tratado violava os interesses nacionais por cessar o tráfico em curto período; maculava a dignidade e comprometia a independência por ser efeito de ingerência da Inglaterra; e usurpava a soberania do Legislativo por implicar leis à revelia dos representantes nacionais, eles sugeriam o desejo de punição e até de excreção do ministro signatário (PARRON, 2011,p.77).

esperavam abolir a Convenção. Desde 1827, deputados da oposição evocavam o tratado para atacar o Executivo. A Lei da Regência, de 14 de junho de 1831, deixa transparecer o aprendizado político deste período. Acordos internacionais, agora, só com aprovação da Assembléia.

Fortes tensões marcaram o pós-abdicação, estimulando a busca de reformas políticas com reflexos no campo social. Nesse período, ocorreu uma politização das questões escravistas e não uma política da escravidão. Política esta gestada após a promulgação da lei de 7 de novembro de 1831, quando proprietários e parlamentares tomaram consciência que o fim do tráfico não demoraria e iniciaram a construção de uma sólida política da escravidão.

A lei de 7 de novembro de 1831, "não deve ser entendida meramente como prescrição normativa nem simulação diplomática mas sim como extraordinário 
ponto de articulação, na história brasileira, entre ação legal e interação social” ( PARRON, 2011, p. 90). Parron insiste:

qualquer análise do porvir da lei da 7 de novembro de 1831 e da formação de uma reação pró-contrabando negreiro deve inter-relacionar as ações de resistência escrava, os desempenhos econômicos regionais, os efeitos do abolicionismo anglo-saxão e a conjuntura das disputas políticas no Império do Brasil (PARRON, 2011, p. 91).

No campo econômico, dos três produtos básicos de exportação, algodão, açúcar e café, apenas o último se mantinha em expansão. Tem-se, ainda, que três revoltas marcaram o campo político na década de 1830: Carrancas (Comarca do Rio das Mortes), Malês (1835) e, na Comarca de Vassouras, o levante de Manuel Congo. As revoltas tiveram reflexos na política-institucional, o Parlamento e as Províncias reagiram com pacotes de segurança pública, ofícios e posturas.

Para aquilatar o peso das lutas dos escravizados para o fim do tráfico e da escravidão, faz necessário examinar cuidadosamente, cada articulação contestatória, pois nem todas produzem o mesmo efeito. "Revoltas escravas são, sem dúvida, fenômenos sociais de indisputável importância, mas isso não as credencia imediatamente como episódios com impacto dissolvente na dinâmica do Império" (PARRON, 2011, p.102-103).

Para o autor, não se pode falar de política da escravidão para o período de 1826 -1835, isto é, durante a primeira década do regime representativo. Tempo de muitos discursos pró-escravidão e tráfico, mas de pouca efetividade. Entretanto, ao longo desse período, as iniciativas pró-escravistas penetraram fundo nas entranhas do poder. Por volta de 1838, com a volta dos conservadores ao poder, "percebe-se, então, pela primeira vez no Brasil independente, uma estreita conexão de grupos sociais e políticos em torno da reabertura do tráfico sob a forma de contrabando em nível sistêmico" (PARRON, 2011, p.103). 


\section{Defesa pública do tráfico}

A consolidação partidária no Brasil, "coincidiu com as primeiras defesas públicas do tráfico e da escravidão desde os escritos da década de 1820" (PARRON, 2011, p.124) . Constatação questionadora da afirmação recorrente de que o tráfico e a escravidão não tiveram defesa pública no Brasil.

Para o autor, o tráfico negreiro na forma de contrabando, ao longo dos seus 20 anos, e a escravidão tiveram a anuência de autoridades e estadistas imperiais. Entre a Abdicação (1831) e o Ato Adicional (1834), a lei de 7 de novembro de 1831 não foi contestada por razões políticas, mas a partir de 1834, a crítica e os pedidos de derrogação ganharam espaço no cenário político.

Feijó, candidato à Regência, defende o tráfico e a escravidão.

O artigo 'Do tráfico dos pretos africanos' pode ser entendido como a primeira resposta de um político célebre à iminente recidiva do tráfico negreiro, numa conjuntura assinalada pela ampliação do mercado global, pelo colapso das Índias Ocidentais, pelo abolicionismo britânico e, finalmente pela nova fase política brasileira aberta com o Ato Adicional (PARRON, 2011, p. 132).

No entanto, Feijó ao ser eleito praticou uma vigorosa política anti-contrabando.

Entre os tópicos da pauta política do partido do Regresso, futuro núcleo histórico do Partido Conservador, criado pelos políticos derrotados para regente, figurava a defesa do contrabando e a garantia da propriedade escrava ilegal.

As forças políticas conservadoras, gradualmente, instauraram a "política do contrabando negreiro" no país, que acabou transformando um problema jurídico ou econômico numa política parlamentar que se opunha ao antiescravismo em todas as esferas da sociedade. "Da crítica à lei, os líderes regressistas tinham passado à defesa do contrabando" (PARRON, 2011, p. 148), defesa expressa nos vários pedidos de revogação da lei, nas várias representações hostis à lei vindas das representações municipais (Mangaratiba, Arreias e Vila do Presídio entre outros). 
Contudo, a Câmara dos Deputados não apreciou integralmente a lei, em parte devido à ameaça inglesa (Bill Parmerston) e ao fato de que a anulação da lei traria dificuldades para o país. Para o autor, "realmente, enquanto os líderes do Regresso auferiam apoio sólido por meio do contrabando” (PARRON, 2011, p.163), com uma agenda definida, os líderes da oposição, os liberais, encontravam-se divididos. Daí as perguntas: "qual é a geografia de sua agenda [do Regresso] e quem eram os atores locais que aceitaram transformar uma questão policial (a perpetração de um crime) em assunto social e político"? (PARRON, 2011, p.163).

O eixo Rio-Vale-Minas absorvia grande parte dos escravos contrabandeados, dando uma conotação regional ao tráfico. Uma pujante integração e acumulação mercantil da região e os novos proprietários rurais, descendentes de burocratas e dos negociantes de grosso trato, constituíam a base social da nova comunidade mercantil, que contava com o apoio de casas comerciais inglesas. "Pode-se dizer, pois, que as relações sociais e políticas que estabilizavam a base da demanda no Brasil foram fundamentais na composição das redes mercantis mais amplas que fechavam o circuito internacional do contrabando” (PARRON, 2011, p.171).

A presença da escravidão no crepúsculo e na alvorada do Império convida o estudioso a ter presente a complexidade da política Imperial que ultrapassa a oposição conservador-liberal e ainda a levar em conta as especificidades do contrabando. Para Parron, -

pode-se falar na fase do contrabando residual (1831-1834/5), quando atividades do comércio não contaram com apoio explicito ou coeso de parlamentares e o discurso a respeito do tráfico o repelia fortemente na esfera pública; e a fase do contrabando sistêmico(1835/6-1850), quando o tráfico atingiu níveis de inédita intensidade e repousou em estadistas e parlamentares engajados na sua preservação ( PARRON, 2011, p. 173). 


\section{Defesa da escravidão na prática legislativa}

Para o autor, há relações entre a maioridade de D. Pedro II (1840), obtida graças ao golpe dos liberais e aliados, e a pressão bélica da Grã- Bretanha, em 1850. São reações ao projeto saquarema de dar uma cobertura sistemática ao tráfico negreiro transatlântico. Para perceber tais relações, visita o início do Segundo Reinado examinando o projeto da Lei de Terra (1842-1850), o Bill Aberdeen (1845) e o fim do comércio negreiro transatlântico (1848-1850).

Frente à nova pressão inglesa, o Brasil reagiu indignado. Os discursos anglófobos e antifilantrópicos pronunciados na Câmara, em 1843, são expressões desta indignação. No entanto, a saída para o duplo impasse, o do contrabando e o do tratado comercial anglo-brasileiro, foi preparada pelos saquaremas entre 1842 e 1844. "No lugar da campanha pela revogação da lei de 1831 (afinal, anulada de facto), conceberam o projeto de terras devolutas, formulado em 1842 e aprovado somente em 1850" (PARRON, 2011, p. 208).

O exame cuidadoso do contexto pode levar-nos ao sentido original do projeto. O texto da lei, preparado por Vasconcelos, visava o tráfico sim, mas principalmente, o trabalho do africano livre, que viria para o Brasil.

Em face do abolicionismo internacionalista, de 1839 em diante, e das revisões dos tratados anglo-brasileiro, entre 1841 e 1844, o projeto da Lei de Terras foi, enfim, uma tentativa bem articulada de institucionalizar o transplante de mão-de-obra barata para o Brasil, incluídos aí africanos, que se supunham cultural e biologicamente acondicionados para a exploração do trabalho em áreas tropicais de fronteira aberta- nesse sentido, a substituição do tráfico negreiro não implicava a instituição do trabalho livre no Brasil à maneira do que havia na Europa, como o fazem crer discursos posteriores emitidos em outro contexto, após a supressão efetiva do contrabando de africanos em 1850 (PARRON, 2011, p. 218-219).

Bill Aberdeen (1845) foi a resposta inglesa ao desafio do governo imperial ao optar por uma política aduaneira autônoma, Tarifa Alves Branco e cancelar o convênio anti-tráfico. Se por um lado isolou o Império do Brasil, por outro, uniu facções partidárias contrárias em torno do tráfico. 
Dois documentos o comprovam: o Protesto do Governo Imperial contra o Bill Aberdeen, de Limpo de Abreu (1798-1883) e a obra Inglaterra e o Brasil tráfico de escravos, que tudo indica ser de autoria de J. M. Pereira. Para Parron, "tratam-se de elementos que manifestam a hegemonia saquarema, construída no interior da jurisdição de um Estado nacional, mas processada conforme as inflexões do sistema interestatal oitocentista" (PARRON, 2011, p. 230).

Com a Bill Aberdeen (1845), o isolamento do Brasil tornou-se uma realidade. Em 1850, após a derrota da moção de Hutt, no Parlamento inglês, que visava desativar a esquadra britânica na África, o gabinete conservador, tendo à frente Eusébio de Queiroz, se movimentou para aprovar a Lei de 4 de setembro de 1850, que tinha por base o projeto de 1837, discutido no gabinete liberal em 1848 . Evitava-se, assim, a guerra com a Inglaterra que parecia iminente, em julho de 1850 .

O grande capital político dos saquaremas facilitou a recepção da lei pelos proprietários de escravos. Acusados de agirem só sob pressão inglesa, o partido do regresso insistiu na idéia de ser a questão do tráfico inteiramente nacional.

Eusébio de Queiroz, no celebre discurso de 16 de julho de 1852, "não apenas despolitizou a dinâmica do tráfico negreiro, mas também internalizou todos os motivos ligados a seu fim, excluindo completamente o papel da Inglaterra" (PARRON, 2011, p. 251). Essa leitura política, para explicar a cisão entre o Estado e o contrabando foi a que vingou na historiografia do século XIX e XX. Para o autor, "definitivamente, o Estado brasileiro em geral e os saquaremas em particular tiveram participação ativa, direta e decisiva no mais volumoso contrabando ilegal de seres humanos de que se tem noticia na história ocidental" (PARRON, 2011, p. 252). 


\section{A era do contrabando e sua política escravista}

Para a historiografia, o apogeu do Segundo Reinado ocorreu entre 1851 e 1865, quando imperou a paz augusta nos trópicos. Para o autor, as consequências diretas e indiretas do fim do tráfico foram ainda pouco estudadas. Daí a questão: É possível pensar e atrelar o seu destino na instituição escravista?

A análise da conjuntura econômica e política do Atlântico e do Brasil oferece pistas explicativas. O Império do Brasil beneficiou-se de um cenário internacional favorável, mas a escassez de mão-de-obra e os altos custos do transporte terrestre impediam um maior aproveitamento. Para parlamentares e fazendeiros, o gargalo da produção brasileira se bem entendido, "se devia não tanto ao fim do contrabando em si quanto ao fato de ele ter ocorrido na ausência da infraestrutura necessária para diminuir os custos de transporte, aumentar a exploração dos escravos agrícolas e atrair imigrantes europeus" (PARRON, 2001, p. 273). Uma saída provisória veio do tráfico interprovincial.

O cativeiro oferecia a chave de leitura dos fatos internacionais e nacionais. Parlamentares e senadores do Império olhavam os Estudos Unidos escravocrata como modelo, antes da guerra civil, e Cuba a ser imitada na sua prática escravista.

Politicamente, na década de 1850 reinou a paz e a Conciliação; no entanto, mudanças ocorriam. Após 1853, Dom Pedro II passou a usar o Poder Moderador não apenas reativamente, como ocorrera entre 1840 e 1853, mas de modo efetivo, apresentando proposta para a legislatura de 1853-1856. “A Conciliação era uma forma de promover o rodízio dos políticos para manter a estabilidade da política” (PARRON, 2011, p. 279).

Como explicar a Conciliação? Os estudos históricos apontam inúmeras causas, corretas por sinal, mas esquecem que "Dom Pedro II soube aproveitar a nova conjuntura e a idéia da conciliação, então em voga, para dar-lhes um sentido próprio" (PARRON, 2011, p. 280). Sem contudo, exercer uma hegemonia política, super omnia et per omnia, assim, na questão da escravidão permaneceu dentro dos 
limites estabelecidos pelos seus diplomatas. Na verdade, diz o autor, "o imperador não apenas aceitou os limites que os líderes políticos colocaram em matérias administrativas, eleitorais e financeiras, mas também seguiu as balizas que fixaram a respeito do cativeiro negro no Brasil” (PARRON, 2011, p. 286-287).

Ter presente que a instituição do cativeiro era legal no país ajuda-nos a entender a nova política da escravidão baseada em:

i) blindar o Parlamento contra discussões sobre o cativeiro; ii) fomentar a imigração livre para obter fonte paralela- e não excludente- de mão-deobra barata; iii) e assegurar fluxos estratégicos de cativos, como o tráfico interprovincial, o deslocamento dos escravos urbanos para o campo e o retorno dos que se abalavam para as republicas vizinhas, onde o cativeiro não gozava reconhecimento legal (PARRON, 2011, p. 287-288).

Os governantes buscavam, então, conduzir a administração sem tocar ou trazer à tona a questão da legalidade institucional da escravidão. A estratégia era alijá-la da agenda política. "Desta forma, os pareceres do Conselho de Estado, os atos dos líderes do governo e o silêncio imposto no Parlamento fixaram, claramente, os limites macropoliticos à discussão do cativeiro no Império do Brasil“ (PARRON, 2011, p. 299-300). O que é confirmado por vários episódios como o da criação da Lei de Terras.

O exame da Lei de Terras permitiu ao autor, na esteira da obra de Lígia Osório Silva (SILVA, 1996), desvelar a sua intenção primeira: “o assentamento de imigrantes europeus em pequena propriedade (núcleos coloniais) mediante a compra de lotes originários das terras devolutas" (PARRON, 2011, p.305). Sua dinâmica era vista como imigração oficial e enquanto não ocorria a chegada de imigrantes financiava-se a vinda de colonos, imigração particular.

Para os políticos que pensavam em colonização, o modelo a ser seguido era o dos Estados Unidos, que criaram condições concretas para que ela ocorresse sem excluir a permanência da escravidão. Em todo esse período, impressiona a diuturna defesa da escravidão no Brasil. 
A mudança ocorreu em 1850, quando se passou a defender a estratégia da reprodução vegetativa das escravarias fazendo eco ao receituário presente desde 1830 em Manuais Agrícolas', em geral, escritos após 1831. "Em uníssono, o que os proprietários do Vale e esses parlamentares partilhavam era a convicção na confluência de longo prazo entre imigração espontânea e crescimento do cativeiro à maneira dos Estados Unidos" (PARRON, 2001, p. 312).

Na era do pós-contrabando (1850-1865), o tráfico inter-provincial, em geral de escravos urbanos e de áreas não açucareiras, teve um crescimento exponencial, alimentado pelo capital do extinto contrabando e pelo desempenho da política parlamentar, que deu estabilidade institucional para as transações comerciais. "Repelindo propostas no Legislativo, seguiu o parecer de 1853 do Conselho de Estado e procurou induzir o fluxo de cativos nos níveis intrarregional, interprovincial e internacional" (PARRON, 2011, p. 317).

Além disso, tratados com Peru (1851), Uruguai (1851) e Argentina (1857) foram assinados para preservar o sistema escravista, a propriedade escrava.

A guerra civil nos Estados Unidos rompeu o quadro institucional cuidadosamente montado pelo Império Brasileiro para preservar a instituição escravista. Após a declaração de Abraham Lincoln, libertando os escravos confederados, em $1^{\circ}$ de janeiro de 1863 , William Christie, representante britânico no Rio de Janeiro, cobrou do Império a emancipação dos escravos livres e dos ilegalmente introduzidos no Brasil, após o sete de novembro de 1831.

O futuro da escravidão se faz presente na agenda parlamentar, forçado pela conjuntura internacional e reforçado pelo pedido do próprio Imperador. "A partir de 1867, finalmente, também conseguiu inscrever a discussão da 'reforma servil' na pauta do Conselho de Estado, onde, ao contrário da década anterior, os membros se manifestariam em favor do fim gradual da instituição" (PARRON, 2011, p. 324).

\footnotetext{
${ }^{1}$ Para uma análise dos Manuais Agrícolas, ver Marquese,2004.
} 


\section{Pontuações}

Acompanhando, comentando e resenhando textos sobre a diáspora, desde 1992, tenho entrado em contato com a rica e diversificada produção historiográfica brasileira, com sua diversidade de temas, métodos e perspectivas analíticas.

Relembro este dado para dizer que o texto de Tamis Parron, $A$ política da escravidão no Império do Brasil, 1826-1865, é um dos mais instigantes que resenhei. Instigante pela temática estudada, pela amplidão da pesquisa e pela refinada análise apresentada.

Sem dúvida, passará a ser uma referência básica para se entender a estabilidade adquirida pela instituição da escravidão no país, por cobrir lacunas e sinalizar para inúmeras veredas a ser pesquisadas no campo historiográfico brasileiro. Texto recomendado a todos os interessados numa leitura mais atenta do nosso passado, leitura que pode ajudar no entendimento das sombras ainda presentes no país, tanto nos seus rincões, quanto nos seus centros urbanos.

Heranças da casa-grande ainda se fazem presentes em nossa sociedade. " $\mathrm{O}$ Brasil tem o maior número de empregados domésticos do mundo e desenvolve inéditas modalidades de servilismo" (CARTA, 2013, p. 12).

Realçamos a seguir uns poucos entre tantos tópicos importantes no âmbito historiográfico. O autor deixa claro, que se faz necessário rever uma fala ainda corrente, tanto entre estudiosos como entre o público em geral, que a lei de 1831, foi para inglês ver. Pois ela constituiu-se no ponto de partida para proprietários e parlamentares darem início à construção de uma política da escravidão. "Nesse sentido, ela não deve ser entendida meramente como prescrição normativa nem simulação diplomática, mas sim como extraordinário ponto de articulação, na história brasileira, entre ação legal e interação social” (PARRON, 2011, p. 90). 
Ainda vige na historiografia a opinião, devido à falta de estudos aprofundados, de que no século XIX não ocorreram defesas da escravidão e do tráfico negreiro no Brasil (PARRON, 2011, p. 124), posição que invisibiliza o conluio de altos políticos do Império do Brasil com o tráfico ilegal (PARRON, 2011, p. 173).

Aponta, ainda, para a necessidade de se matizar a análise do contrabando, mostrando ser ele no Brasil não um fenômeno de envergadura nacional. Sua maior incidência se deu no eixo Rio-Vale-Minas².

À luz desses dados, supor que o contrabando fosse um fenômeno de envergadura nacional é o primeiro passo para descompreender não apenas seu significado social, mas também seu impacto sobre articulações políticas. Ao contrário, ele foi fruto de interesses regionais que se sobrepuseram aos de outras áreas brasileiras, submetidas assim a enormes custos diplomáticos de uma ação antijurídica (para dizer o mínimo), sem fluir seus supostos benefícios (PARRON, 2011, p. 164).

Para o autor, outro tópico que precisa ser matizado, com base numa leitura mais crítica das fontes é o das articulações entre insurreições escravas e a política nacional. Relembrando: "Revoltas escravas são, sem dúvida, fenômenos sociais de indisputável importância; mas isso não as credencia imediatamente como episódios com impacto dissolvente na dinâmica do Império” (PARRON, 2011, p. 102-103).

A sugestiva apresentação das fases relacionadas com o contrabando, fase do contrabando residual (1831-1834/5) e fase do contrabando sistêmico (1835/6 1850) deve ser entendida como uma contribuição do autor, frente à questão (PARRON, 2011, p. 173).

Parron indica temas que merecem ser mais estudados e aprofundados como: o significado da lei da terra na década de 1840 (PARRON, 2011, p. 209); os efeitos da supressão do contrabando tanto na política imperial, quanto na sobrevida da escravidão (PARRON, 2011, p. 270). Na verdade, o centro-sul, em especial, o eixo

\footnotetext{
${ }^{2}$ Para uma visão ampla da presença escrava no Vale, ver Salles, 2008.
} 
Rio de Janeiro, Vale do Paraíba e Minas Gerais contribuíram para preservar a sociedade escravocrata.

Não apenas os políticos do centro-sul postularam com maior frequência a sobrevida do cativeiro no Brasil, como também entre eles houve troca de gerações . Coube sobretudo a moços como Raimundo Araújo Lima, Paulino e, mais tarde José de Alencar, Domingos Andrade Figueira e Antonio Ferreira Viana argumentar em favor do trabalho forçado no Império (PARRON, 2011, p. 312).

Parron abre, em alto nível, um diálogo a ser feito na historiografia, entre política e escravidão. Munido de uma vasta documentação, amealhada nos arquivos do Itamaraty, da Biblioteca Nacional e do Instituto Histórico Geográfico explicita os laços estreitos entre a política e a escravidão no Império. Ligação responsável pela longa duração da escravidão de ontem e pelas estruturas escravagistas presentes no imaginário da sociedade brasileira e que se perpetuam nas relações de trabalho no Brasil. "Sim, o país do futuro é estranhamente obsoleto e continua a pagar caro por três séculos e meio de escravidão” (CARTA, 2013, p.12).

\section{REFERÊNCIAS}

CARTA, Mino. Editorial. A herança da Casa-Grande. Revista Carta Capital, São Paulo, ano XVIII, n. 732, p.12, 2013.

MARQUESE, Rafael de Bivar. Feitores do corpo, missionários da mente: senhores, letrados e o controle dos escravos nas Américas, 1680-1860. São Paulo: Companhia das Letras, 2004.

PARRON, Tamis. A política da escravidão no Império do Brasil, 1826-1865. Rio de Janeiro: Civilização Brasileira, 2011. ISBN 978-85-200-1023-5, p. 373.

SALLES, Ricardo. E o Vale era o escravo. Vassouras, século XIX. Senhores e escravos no coração do Império. Rio de Janeiro: Civilização Brasileira, 2008.

SILVA, Lígia Osório. Terras devolutas e latifúndio: efeitos da lei de 1850. Campinas: Ed. Unicamp, 1996. 